\title{
PHARMACOLOGICAL AND MEDICINAL CHEMISTRY ASPECTS OF CANNABIS COMPOUNDS
}

\author{
Tamara Cotelea \\ USMF “N. Testemițanu” facultatea Farmacie, str.Malina Mica 66, Chişinau, Republica Moldova, \\ e-mail: tamara777@bk.ru,phone:+37322285979
}

\begin{abstract}
The current communication includes a general overview of the scientific interest and medicianl chemistry aspects of Cannabis compounds. It relates to metabolism, pharmacological action and phisico-chemical analysis of these compounds, as well as of some isomers differing in spatial arrangement of functional groups.
\end{abstract}

\section{Introduction}

Cannabis is one of the first plants utilized by humans as non-food product. Hashish was implimented in nothern China cca. 5000 or 6000 years ago and the plant itself served for textile production. During the first centuries B.C. the first samples of Cannabis paper have ben produced. During the following periods Cannabis was considered in China as a basic crop. It was also used in India in falk medicine, for ritual purposes and also for textile fibers. Aproximatively 1000 yrs. B.C. cannabis appeared in Europe. It was a result of human migrations from Black Sea to Midle Asia and other nearby areas. It was considered a sacred plant in Siria, Egipt and northen Africa. During the midle ages due to its remarcable stability to salted water it was intensively used for marine rope production. It also penetrated America form North to South during the 16-th century. Development of chemical industru during 19-th and 20-th centuries has led to a decline in Cannabis cultivation.

\section{Botanical characterisation}

Two basic varieties of Cannabis are known: Cannabis sativa and Cannabis Indica. They are widely spread in temperate and tropical regions of the Earth. Branching degree depends on the climatic conditions. The size of the composite leaves varies depending on the plant height. Flowers represent masculine (stamen carriers) and feminine (pistils carriers) inflorescents. Masculine inflorescences are tipically more flower-abundant (see pictures below).

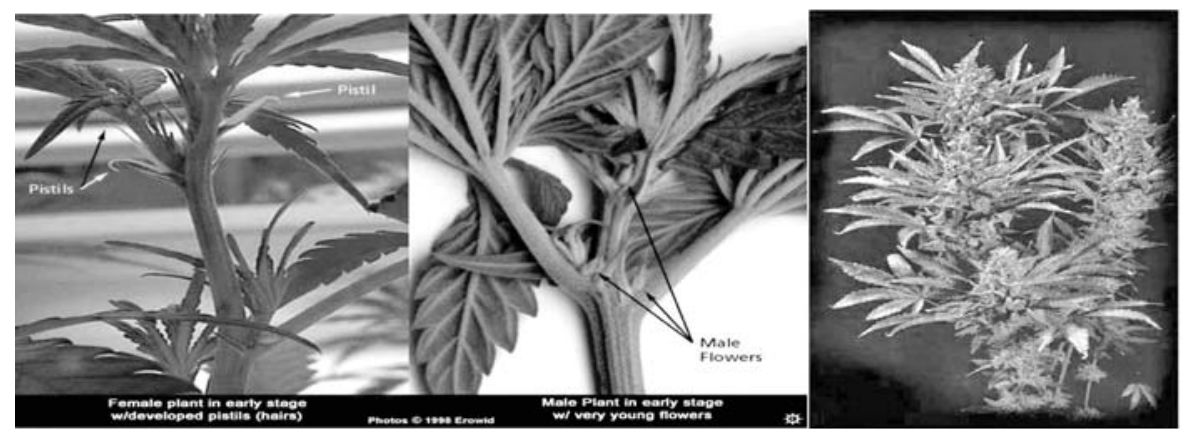

\section{Cannabis halucinogenic compounds}

Marijuana represent the finely cut plant, including inflorescents, having the appearence of a usual tea. It can be identified by its specific soil-like smell of crashed Cannabis. Hashish is a brown resin. Usually in drug abuse practices is used in the shape of small balls, called in slang "cakes". It can be smoked or chewed, sometimes it is applyed directly to the gums by friction. Hashish oil represent a plant extract with a more powerfull action, since one drop of oil into a cigarette equivalents to one hashish pipe.

\section{Chemical composition of Cannabis}

The basic compounds to cause phisiological efeects are cannabinoids. The plants also contain nitrogen organic substances like proteins, glucoproteins and enzimes. The spectrum of known components also includes simple alcohols, aldehydes, ketones, fatty acids, esters and lactones, terpenes, steroids, fenolic compounds as well as flavonoid glicosides. 
a)<smiles>CCCCCc1cc(O)c2c(c1)OC(C)(C)c1ccc(C)cc1-2</smiles>

b)

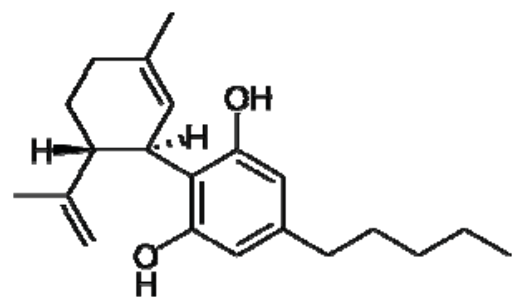

Figure 1

The most abundant components with confirmed activity are cannabinol (a) and cannabidiol (b) (Figure 1). It is considered that canabinol is not a plant catabolism product, but an artefact derived from plant conservation [5]. Tetrahidrocannabinol (THC) is administered under the name Dronabinol and is a part of medical preparations known as Merezine, Marinol. It represent a remedy in the case of anurexia in AIDS patients, conected to abrupt weight loss, nausea and sickness, chemiotherapy side effects in cancer patients where other usual preparations are not effective. For this purpose THC is administered in doses of 2 to $20 \mathrm{mg}$ per day in tablets or capsules for oral usage. THC is absorbed almost entirely (90-95\%) after oral administration. Due to combined effects of liver metabolism and encreased lipophylicity only $10-20 \%$ of the dose reach the blood stream. THC has a large repartition volume, almost 101/kg and more then $95 \%$. It is bounded alon with derived metabolites to sanguin proteins. THC elimination phase is caracterized by a bicompartimental model with an initial phase having the elimination period of 4 hours and the $\beta$ - phase having the elimination period from 25 to 36 hours. Due to the large repartition volume, THC metabolites can be detected in urine at minimal level for a long period of time.

\section{Marijuana intoxication symptoms}

Patients of marijuana abuse present chronic coughing, red eyes, fatigue, exagerated appetite, attraction to drugs, drowsiness, sensitivity to viral infections, sclerotic dysfunction, impaired speech, difficulty in communication, abrupt change from passive to aggressive mood, dizziness. The pictures below are sugestive in this context.
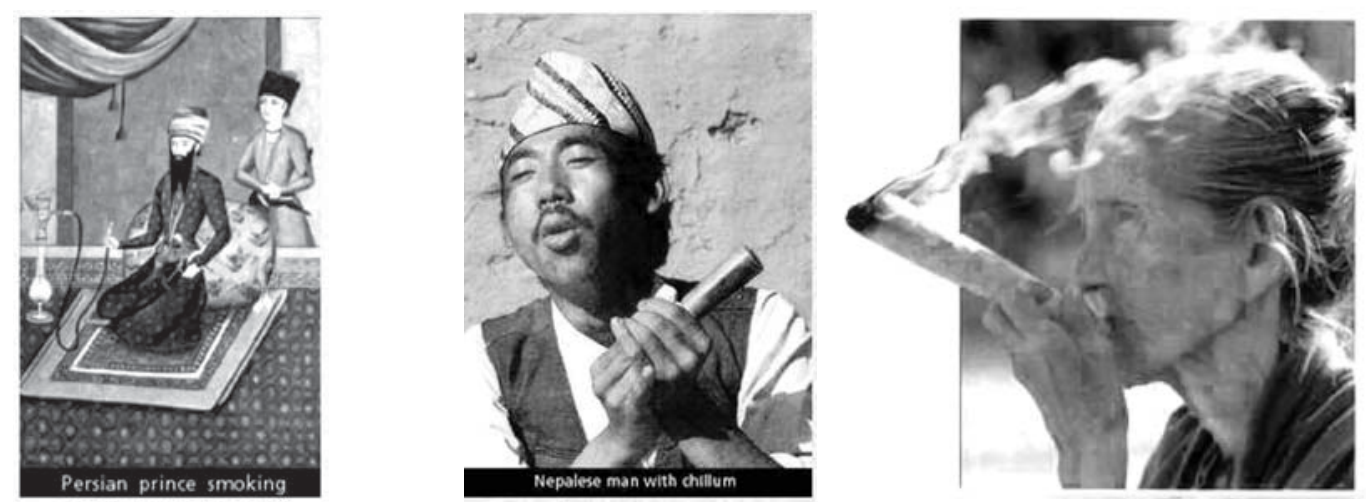

Analgesic properties of marijuana compounds

Although the analgesic properties of marijuana are known since 2000 years ago, investigation of anti-nociceptive role of cannabinoids turned out to be difficult, since their receptors were unknown. The interest towards analgesic properties of marijuana has encreased gradually in the 19-th century.

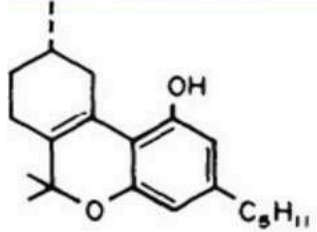

(IS) $-\Delta^{3}-T H C$

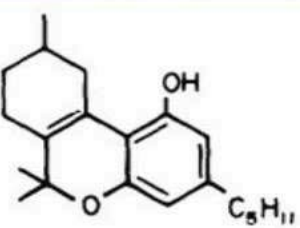

(IR) $-\Delta^{3}-T H C$

The racemic mixture of enantiomeric cannabinoids $1 S$ - $\Delta^{3}$-THC and $1 R-\Delta^{3}$-THC have been synthesized in 1940 . The oral use of cannabis has been reported to sucsessfully alleviate labor pain, as well as other pain-related states. The 
systematic study of analgesic compounds and their action mechanism hs been initiated in the late 90-s of the last century and is connected to the discovery of cannabinoid receptors. They are located in the brain (talamus, hippocampus) and spinal cord. A special breakthrough was made in 1992 with the discovery of an endogen compound with the ability to bind to cannabinoid receptors. It is a derivative of arachidonic acid (arachidonyl-ethanol amide) called trivially anandamide (deriving from ancient sanscrit meaning happiness). Its action is similar to that of THC. Besides, a large number of cannabinoids have been produced synthetically. They have proved to be efficient anti-nociceptive agents and inflamation modulators.

THC is metabolized intensively in liver by oxidative degradation processes. The obtained metabolites posess different activity and could be detected in the urine [1,7]. Their elimination takes place via gastro-intestinal and urinary pathways. For analytical detection an extraction step is mandatory, followed by HPLC analysis on RP columns. Hyphenated techniques, such as LC-MS and GC-MS lower the detection limits to $0.05-0.01 \mathrm{ng} / \mathrm{ml}$ values $[2,3,4,6,8]$. Identification of metabolized is confirmed by tandem MS-MS experiments.

Acknowledments. Academy of Sciences (Moldova) and CNR (Italy) are acknowledged for financial support (bilateral project 11.820.08.01/ItF "Novel approaches for the synthesis of optically active cannabinoids with relevant biological activity and therapeutical potential" 2011-2012).

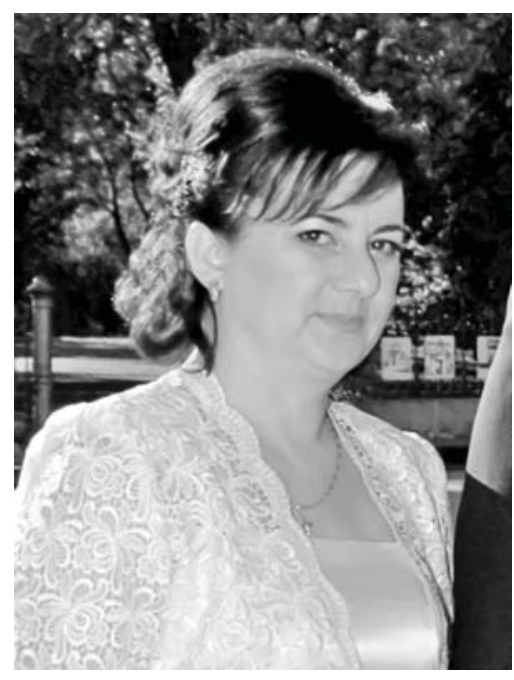

Dr. Tamara Cotelea was born on june 26, 1959 in Butesti village, Glodeni district, Republic of Moldova. She graduated from the Pharmacy Department of „N. Testemitanu” State Medical and Pharmaceutical University and worked as a pharmacist. Starting from 1991 she was a didactic staff of the Pharmacy Department, chair of pharmaceutical and toxicological chemistry. She got the PhD in 2002 with prof. Filip Babelev and in 2005 was appointed Assistant Professor, responsible for teaching courses. In the period 20052007 Dr. Cotelea was an expert of Drug Agency, member of the pharmaceutical evaluation and coordination for implementing GMP practices Board. She has contributed with more then 60 papers in the field of drug research. The main research area relates to analytical chemistry, specifically implementation of physico-chemical methods of analysis of drugs in complex matrix. She is a member of the International Association of Forensic Toxicologists.

\section{References}

[1]. Balabanova, S.; Arnold, P.J.; Luckow, V.; Brunner, H.; Wolf, H.U. Tetrahydrocannabinole in haar von haschischrauchem. Z.Rechtsmed. 1989, 102, pp. 503-508.

[2]. Baumgartner, W.A.; Chen-Chih, C.; Donahue, T.D.; Hayes, G.F.; Hill, V.A.; Scholtz, H. Forensic drug testing by mass spectrometric analysis of hair. In: Forensic applications of mass spectrometry. Ed. Jehuda Yionon. London, Tokyo. CRC Press: Boca Raton, Ann Arbor, 1995. pp. 61-94.

[3]. Baumgartner, W.A.; Hill, V.A.; Baer, J.D.; Lyon, I.W.; Charuvastra, V.C. Detection of drug use by analysis of hair. J. Nucl. Med. 1988, 29( 5), p. 980.

[4]. Crimele, V.; Kintz, P.; Mangin, P. Testing human hair for cannabis. Forensic. Sci Int. 1995, 70, pp. 175-182.

[5]. Crimele, V.; Satchs, H.; Kintz, P.; Mangin, P. Testing Human Hair for Cannabis. III. Rapid Screening Procedure for the Simultaneous Identification of delta-9-tetrahydrocannabinol, Cannabinol and Cannabidiol. J.Anal. Toxicol. 1995, 20, pp. 13-16.

[6]. Clarke's isolation and identification of drugs in pharmaceuticals, body fluids and post-mortem material. Ed. Moffat, A.C. The Pharmaceutical Press. London. 1986.

[7]. El-Sohly, M.A. Urinalysis and casual handing of marjuana and cocaine. J.Anal. Toxicol. 1991, 15. p. 46.

[8]. Fihbein, L. Chromatography of environmental hazards. V. IV. Drugs of abuse. Elsevier scietific publishing company. Amsterdam, Oxsford, New York. 1982. 